\title{
Modulatory effect of prostaglandins on human monocyte activation for killing of high- and low-virulence strains of Paracoccidioides brasiliensis
}

\author{
A. M. V. C. SOARES, ${ }^{*}$ S. A. CALVI, $\dagger$ M. T. S. PERAÇOLI, ${ }^{*}$ A. C. FERNANDEZ, ${ }^{*}$ L. A. DIAS* \& A. R. DOS ANJOS* \\ *Department of Microbiology and Immunology, Biosciences Institute, and $\uparrow$ Department of Tropical Diseases, Medical School, \\ UNESP, Botucatu, S.P., Brazil
}

\begin{abstract}
SUMMARY
The effect of indomethacin (Indo), a cyclo-oxygenase inhibitor, on the monocyte-mediated killing of a low- $(\mathrm{Pb} 265)$ and a high- $(\mathrm{Pb} 18)$ virulence strain of Paracoccidioides brasiliensis was examined. The Pb18 strain was not killed by either non-activated or interferon- $\gamma$ (IFN- $\gamma$ ) -activated human monocytes but these cells did show fungicidal activity if pretreated with Indo. In contrast with IFN$\gamma$, tumour necrosis factor- $\alpha(\mathrm{TNF}-\alpha)$ was very effective at stimulating the fungicidal activity of monocytes. While the low-virulence strain, $\mathrm{Pb} 265$, could not be killed by monocytes, cells preincubated with IFN- $\gamma$ demonstrated fungicidal activity. The killing of this strain was also induced by pretreatment of monocytes with Indo. The results suggest a negative role for prostaglandins, which are synthesized via the cyclo-oxygenase pathway, in the regulation of monocyte-mediated killing of virulent and avirulent strains of $P$. brasiliensis and that TNF- $\alpha$ generation during the fungus-monocyte interaction is more important in the killing of $\mathrm{Pb} 265$ than $\mathrm{Pb} 18$.
\end{abstract}

\section{INTRODUCTION}

Paracoccidioidomycosis is a deep mycosis which is endemic in Latin America. This disease is caused by Paracoccidioides brasiliensis, a fungus that undergoes thermal dimorphism, developing as a yeast at body temperature and as a mycelium at room temperature. ${ }^{1}$ The clinical manifestations of the disease are those of a chronic granulomatous disease with involvement of the lung, reticuloendothelial system, mucocutaneous areas and other organs. ${ }^{2}$ Studies on experimental infection with $P$. brasiliensis have shown an involvement of polymorphonuclear neutrophils and resident macrophages in the development of the lesions already observed in the early phases of the infection. ${ }^{3}$ However, these cells do not appear to be fungicidal for $P$. brasiliensis in vitro. ${ }^{4-6} \mathrm{~A}$ significant fungicidal activity was only obtained after macrophage activation by interferon- $\gamma$ (IFN- $\gamma$ ) by a mechanism other than the generation of reactive oxygen metabolites. ${ }^{7}$ However, studies from our laboratory on the modulation by cytokines of $P$. brasiliensis growth in macrophages have suggested that IFN- $\gamma$ does not activate human monocytes or macrophages for killing of virulent

Received 8 October 1999; revised 4 April 2000; accepted 2 November 2000 .

Correspondence: Dr A. M. V. C. Soares, Department of Microbiology and Immunology, Biosciences Institute, UNESP, CEP:18618-000-Botucatu, São Paulo, Brazil. strains of $P$. brasiliensis in vitro. This cytokine is important for effective killing by human monocytes or macrophages when challenged with a low-virulence strain of the fungus.

Prostaglandins are synthesized by a variety of activated cell types during the course of arachidonic acid metabolism, through the cyclo-oxygenase pathway. Macrophages are an important source of prostaglandin $\mathrm{E}_{2}\left(\mathrm{PGE}_{2}\right)$, which has been shown to play a critical role in modulating host immune responses. ${ }^{8}$ This mediator has been shown to suppress various lymphocyte functions, such as T-lymphocyte proliferation ${ }^{9}$ and lymphokine secretion by antigen-activated lymphocytes, ${ }^{10}$ as well as to inhibit Ia antigen expression on macrophages. ${ }^{11}$ Moreover, in the murine system, $\mathrm{PGE}_{2}$ decreases interleukin-2 (IL-2) and IFN- $\gamma$ production by T helper type 1 (Th1) subsets but not the production of IL-4 by Th2 cells. Some models of interaction between phagocytic cells and micro-organisms have suggested that secretion of $\mathrm{PGE}_{2}$ elicited by intracellular parasites induces unresponsiveness of macrophages to IFN- $\gamma \cdot{ }^{12}$ In the present investigation we studied the modulatory effect of prostaglandins on the activation process for the fungicidal activity of human monocytes challenged in vitro with high- and low-virulence strains of $P$. brasiliensis.

\section{MATERIALS AND METHODS}

Isolation of peripheral blood mononuclear cells Heparinized venous blood was obtained from healthy adult volunteers with informed consent. Peripheral blood 
mononuclear cells (PBMC) were isolated by density gradient centrifugation at $400 \mathrm{~g}$ for $30 \mathrm{~min}$ on Histopaque [density $(d)=1.077$ ] (Sigma Chemical Co., USA). Briefly, $5 \mathrm{ml}$ of heparinized blood was mixed with an equal volume of RPMI-1640 tissue culture medium (Gibco Laboratories, Grand Island, NY) containing $2 \mathrm{~mm}$ L-glutamine, 10\% heatinactivated human AB serum, $20 \mathrm{~mm}$ HEPES and $40 \mu \mathrm{g} / \mathrm{ml}$ gentamicin (CTCM). Samples were layered over $3 \mathrm{ml}$ of Histopaque in a 15-ml conical plastic centrifuge tube. After centrifugation at $400 \mathrm{~g}$ for $30 \mathrm{~min}$ at room temperature, the interface layer of PBMC was harvested and washed twice with phosphate-buffered saline-ethylenediaminetetraacetic acid (PBS-EDTA) and once with CTCM. Cell viability, as determined by $0 \cdot 2 \%$ Trypan blue exclusion, was $>95 \%$ in all experiments. The monocytes were counted using neutral red $(0 \cdot 02 \%)$ and the mononuclear cells were suspended to a concentration of $2 \times 10^{6}$ monocytes $/ \mathrm{ml}$ in CTCM.

\section{Monocyte monolayers}

The monocyte suspension $\left(2 \times 10^{6} / \mathrm{ml}\right)$ was dispensed as $100 \mu \mathrm{l} /$ well in Linbro Titertek (Flow Laboratories, Inc., Mclean, VA) 96-well flat-bottomed plates. After incubation for $2 \mathrm{hr}$ at $37^{\circ}$ in $5 \% \mathrm{CO}_{2}$, non-adherent cells were removed by aspiration and each well was rinsed twice with CTCM. After adherence, the monocytes were treated at $37^{\circ}$ in $5 \% \mathrm{CO}_{2}$ for $24 \mathrm{hr}$ with the following stimuli: (i) IFN- $\gamma 1000 \mathrm{U} / \mathrm{ml}$ (Genzyme, Corp., Boston, MA); (ii) indomethacin $20 \mu \mathrm{g} / \mathrm{ml}$ (Sigma Chemical Company); (iii) IFN- $\gamma 1000 \mathrm{U} / \mathrm{ml}$ plus indomethacin $20 \mu \mathrm{g} / \mathrm{ml}$; (iv) tumour necrosis factor- $\alpha$ (TNF- $\alpha$ ) 250,500 , or $1000 \mathrm{U} / \mathrm{ml}$ (Genzyme, Corp.); and (v) IFN- $\gamma 1000 \mathrm{U} / \mathrm{ml}$ plus TNF- $\alpha$ 250$\mathrm{U} / \mathrm{ml}$. These stimuli were used to induce monocyte activation for the study of fungicidal activity.

\section{Fungi}

Paracoccidiodes brasiliensis strains 18 (Pb18) and $265(\mathrm{~Pb} 265)$ were maintained in the form of yeast cells at $36^{\circ}$ in Fava Netto's culture medium for 6 days. ${ }^{13}$ Yeast viability was determined by phase-contrast microscopy and bright yeast cells were counted as viable, while dark ones were considered inviable. Fungal suspensions containing more than $90 \%$ viable cells were used for the experiments.

\section{Challenge of monocyte cultures with $\mathrm{P}$. brasiliensis for} evaluation of fungicidal activity

After removal of the supernatants from the monocyte cultures preactivated with the stimuli, the fungicidal activity of monocytes was tested by challenge with $100 \mu$ yeast-form $\mathrm{Pb} 18$ or $\mathrm{Pb} 265$ suspension $\left(4 \times 10^{4}\right.$ viable units $/ \mathrm{ml}$ in CTCM). After co-culture for $18 \mathrm{hr}$ (experimental cultures), cells were harvested with distilled water to lyse monocytes. Each culture and well washing was contained in a final volume of $2 \mathrm{ml}$. To evaluate fungicidal activity, the number of colony-forming units (CFU) of P. brasiliensis was determined by plating $100 \mu \mathrm{l}$ of the $2 \mathrm{ml}$ volume on agar plates containing brain-heart infusion (BHI) agar supplemented with $4 \%$ horse serum and $5 \%$ of $P$. brasiliensis culture filtrate, the latter being the source of growth-promoting factor. ${ }^{14} \mathrm{~A}$ control culture containing only $100 \mu$ l of yeast-form $P$. brasiliensis $\left(4 \times 10^{4}\right.$ viable units $/ \mathrm{ml}$ in CTCM) was submitted to the same procedures and used for the experimental cultures. Inoculated plates were incubated at $36^{\circ}$ in sealed plastic bags to prevent drying. After 10 days, the number of CFU per plate was counted. The percentage of fungicidal activity was determined by the formula: $[1-$ (mean $\mathrm{CFU}$ of experimental culture/mean CFU of control culture) $] \times 100$.

\section{$T N F-\alpha$ assay}

Monocytes cultured as described above were pretreated for $24 \mathrm{hr}$ with the following stimuli: (i) IFN- $\gamma 1000 \mathrm{U} / \mathrm{ml}$, (ii) indomethacin $20 \mu \mathrm{g} / \mathrm{ml}$, or (iii) IFN- $\gamma 1000 \mathrm{U} / \mathrm{ml}$ plus indomethacin $20 \mu \mathrm{g} / \mathrm{ml}$ and after challenge with $\mathrm{Pb} 18$ or Pb265 for $4 \mathrm{hr}$. Supernatants were obtained to determine TNF- $\alpha$ production using a sandwich-type enzyme-linked immunosorbent assay (ELISA). Linbro Titertek (Flow Laboratories, Inc., Mclean, VA) 96-well plates were coated for $18 \mathrm{hr}$ at $4^{\circ}$ with $100 \mu 1$ of monoclonal antibody anti-human TNF- $\alpha$ (Genzyme Corp.) at a concentration of $1 \mu \mathrm{g} / \mathrm{ml}$ in $0 \cdot 2 \mathrm{M}$ carbonate buffer, pH 9.6. In this and all other steps, the wells were washed six times with $200 \mu \mathrm{l} \mathrm{PBS}$ plus $0 \cdot 5 \%$ Tween-20 (T-PBS). After blocking for $2 \mathrm{hr}$ with $5 \%$ casein in PBS at room temperature, standard and samples diluted $1: 2$ were added in duplicate and incubated for $18 \mathrm{hr}$ at $4^{\circ}$. Recombinant human TNF- $\alpha$ (Genzyme Corp.) was used as standard. After washing, the wells were sequentially exposed to a volume of $100 \mu$ l of rabbit anti-human TNF- $\alpha$ polyclonal antibody (Genzyme Corp.) at $1 / 1000$ dilution. The plates were incubated for $2 \mathrm{hr}$ at room temperature. After washing, $100 \mu \mathrm{l}$ of peroxidase-conjugated goat anti-rabbit immunoglobulin G (IgG; Sigma Chemical Co.) at 1/8000 dilution was added. The plates were incubated at room temperature and the wells were then washed with T-PBS, and $100 \mu \mathrm{l}$ of an enzymatic substrate containing $0.4 \mathrm{mg} / \mathrm{ml} o$ phenylenediamine and $2 \mu \mathrm{l} / \mathrm{ml}$ hydrogen peroxide in $0 \cdot 1 \mathrm{M}$ citrate-phosphate buffer, pH 5·2, was added. After 15 min incubation of the plates at room temperature in the dark, the reaction was stopped by the addition of $50 \mu \mathrm{l} 2 \mathrm{M}$ sulphuric acid, and absorbance values were measured at $492 \mathrm{~nm}$ using an ELISA reader (Multiscan Spectrophotometer, EFLAB, Helsinki, Finland). Equivalent concentrations of recombinant human TNF- $\alpha$ were determined for experimental samples by interpolation of the recombinant human TNF- $\alpha$ standard curve run on each assay plate in a serial dilution. The results were expressed as $\mathrm{pg} / \mathrm{ml}$. The lower limit of TNF- $\alpha$ detection for individual assay was $10 \mathrm{pg} / \mathrm{ml}$.

\section{Statistical analysis}

Data were analysed statistically using the INSTAT software (Graph Pad, San Diego, CA). ${ }^{15}$ The results were compared by analysis of variance (ANOvA) followed by the Tukey test, with the level of significance set at $P<0 \cdot 05$.

\section{RESULTS}

\section{Effect of IFN- $\gamma$ on the activation process of human monocytes to kill Pb18 and Pb265}

Figure 1 shows that human monocytes cultivated without a stimulus lacked fungicidal activity against low- and highvirulence strains of the fungus. Moreover, preactivation with IFN- $\gamma$ was only active in endowing human monocytes with fungicidal activity against $\mathrm{Pb} 265$, the low-virulence strain. This cytokine activation for fungal killing was effective independently of the dose employed. The fungicidal activity detected at 


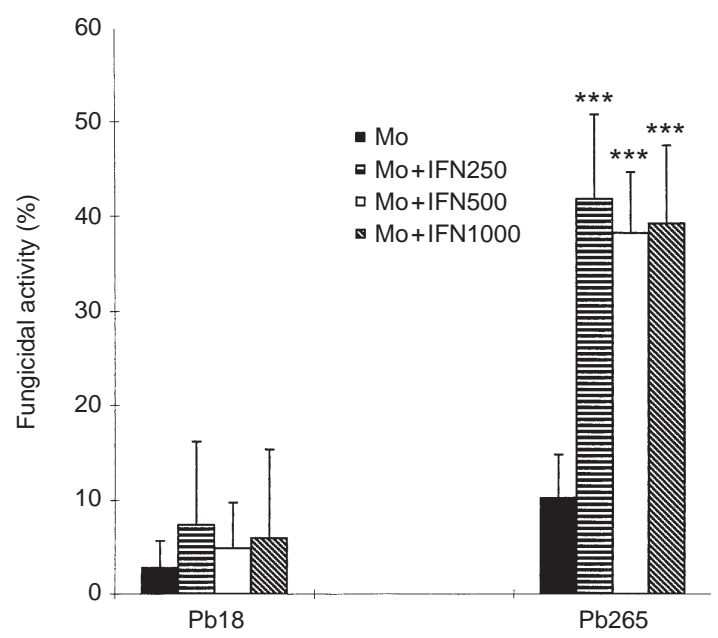

Figure 1. Effect of IFN- $\gamma$ on the fungicidal activity of human monocytes challenged in vitro with high- and low-virulence strains of P. brasiliensis. Monocytes (Mo) were preincubated with CTCM or CTCM plus different concentrations of IFN- $\gamma(250,500$ and $1000 \mathrm{U} /$ $\mathrm{ml}$ ) for $24 \mathrm{hr}$ and after challenge with P. brasiliensis strain 18 (Pb18) or $265(\mathrm{~Pb} 265)$ for $4 \mathrm{hr}$. Results are expressed as mean \pm SEM of percentage of fungicidal activity detected in monocytes obtained from 15 subjects; ${ }^{* * *} P<0 \cdot 001$.

three IFN- $\gamma$ concentrations was significantly higher than that observed in non-activated monocytes.

\section{Effect of prostaglandins on the fungicidal activity of human monocytes preincubated with IFN- $\gamma$ and challenged in vitro with Pb18 and Pb265}

To test if the prostaglandin secretion induced by the fungus is involved in the modulation of fungicidal activity of human monocytes preactivated with IFN- $\gamma$ and challenged with the two $P$. brasilensis strains, we treated the monocytes with indomethacin to suppress the synthesis of these mediators. As shown in Fig. 2, cells treated with indomethacin $(20 \mu \mathrm{g} / \mathrm{ml})$ had a fungicidal action on $\mathrm{Pb} 265$ and $\mathrm{Pb} 18$, indicating that secreted prostaglandins exert a negative autocrine regulation on fungicidal activity in untreated macrophages. In addition, suppression of prostaglandin synthesis by indomethacin induced a significant fungicidal activity in IFN- $\gamma$-activated monocytes, even when they were challenged with the highvirulence strain of $P$. brasiliensis. The results showing that in the absence of prostaglandin even cells non-activated with IFN- $\gamma$ presented a significant fungicidal activity suggest that another cytokine, liberated by monocytes when in contact with the fungus, could be involved in the activation process for an effective killing of $P$. brasiliensis. This cytokine may exert this effect alone or in a synergistic effect with IFN- $\gamma$ when prostaglandin secretion is inhibited. The involvement of TNF- $\alpha$ in our system was tested by evaluation of its level in the several co-culture supernatants, as reported in the 'Materials and methods'. The results were compared with the respective fungicidal activity of the same co-cultures. As shown in Fig. 3, the low fungicidal activity obtained with nonactivated and IFN- $\gamma$-activated cultures challenged with $\mathrm{Pb} 18$ was correlated with low levels of TNF. However, surprisingly,

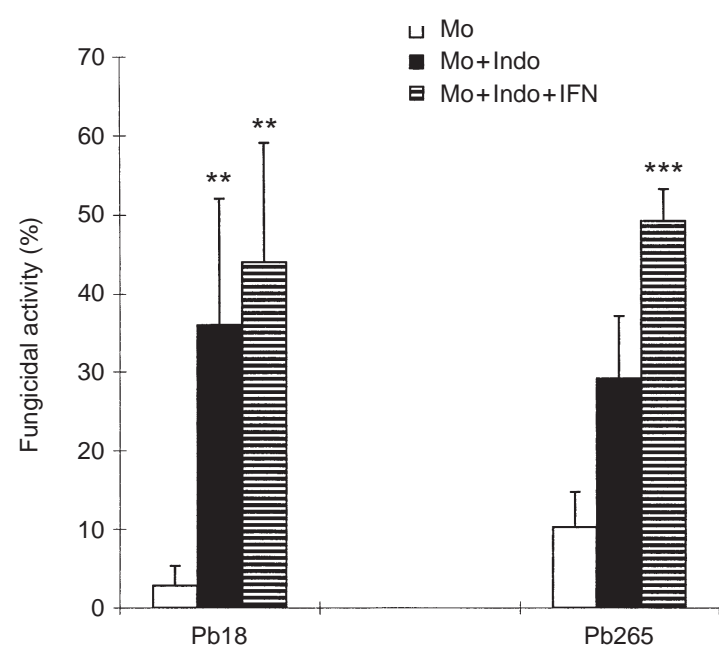

Figure 2. Effect of indomethacin (Indo) on the fungicidal activity of human monocytes non-activated or IFN- $\gamma$-activated and challenged with $\mathrm{Pb} 18$ or Pb265. Monocytes (Mo) were preincubated with CTCM or with CTCM containing Indo $(20 \mu \mathrm{g} / \mathrm{ml})$ or Indo $(20 \mu \mathrm{g} / \mathrm{ml})$ plus IFN- $\gamma(1000 \mathrm{U} / \mathrm{ml})$ for $24 \mathrm{hr}$, after challenge with $\mathrm{Pb} 18$ or $\mathrm{Pb} 265$ for $4 \mathrm{hr}$ and evaluated for fungicidal activity. Results are expressed as mean \pm SEM of percentage of fungicidal activity detected in monocytes obtained from 15 subjects; $* * P<0 \cdot 01, * * * P<0 \cdot 001$.

a significant fungicidal activity was detected with indomethacin alone or indomethacin plus IFN- $\gamma$ treatment and was also related to low levels of TNF- $\alpha$. Analysis of the results for Pb265 showed that, similar to $\mathrm{Pb} 18$, non-activated monocytes presented low fungicidal activity despite the increase in TNF- $\alpha$ levels when compared to Pb18. However, the significant fungicidal activity observed in indomethacin- or IFN- $\gamma$ pretreated monocytes was associated with similar levels of TNF- $\alpha$ when compared to untreated monocytes. Higher levels of TNF- $\alpha$ were only obtained when the cells were incubated with indomethacin plus IFN- $\gamma$. However, the fungicidal activity of this culture was similar to that obtained by pretreatment with indomethacin or IFN- $\gamma$ alone. Taken together, the results show that in the absence of prostaglandins low levels of TNF- $\alpha$ are sufficient for monocyte activation with consequent killing of the virulent strain of $P$. brasiliensis. However, in the presence of prostaglandins two activation signals are necessary for the acquisition of fungus-killing ability, one given by IFN- $\gamma$ and the other given by adequate concentrations of TNF- $\alpha$. These conditions were detected in our system when IFN- $\gamma$-treated monocytes were challenged with $\mathrm{Pb} 265$.

To determine whether, in the absence of prostaglandin production, TNF- $\alpha$, even at low levels, was enough for effective monocyte killing, we carried out experiments in which the cells were preincubated with different doses of TNF- $\alpha$. This preincubation process promotes monocyte activation by TNF- $\alpha$ before the contact of these cells with the fungus, avoiding the action of prostaglandins secreted in the supernatants of the co-cultures. The results are shown in Fig. 4. As expected, TNF- $\alpha$ at different concentrations activated human cells for effective killing of the high-virulence strain of $P$. brasiliensis. The importance of this cytokine was confirmed recently in our laboratory by experiments with monocytes 
$\mathrm{Pb} 18$
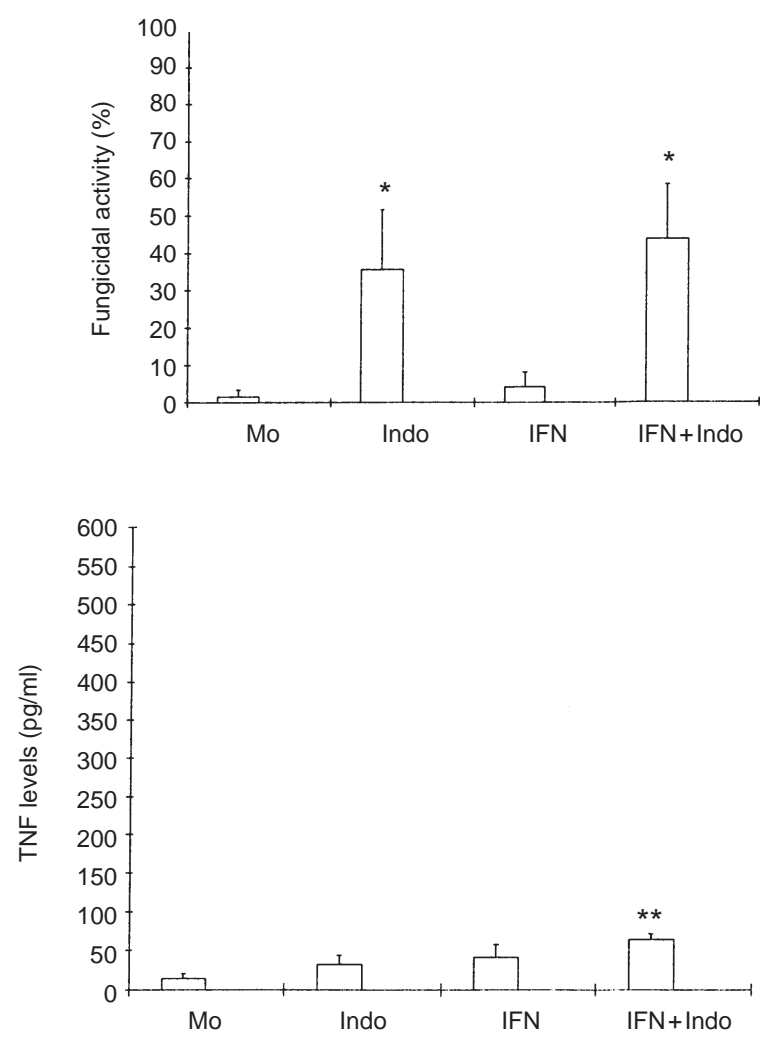

$\mathrm{Pb} 265$
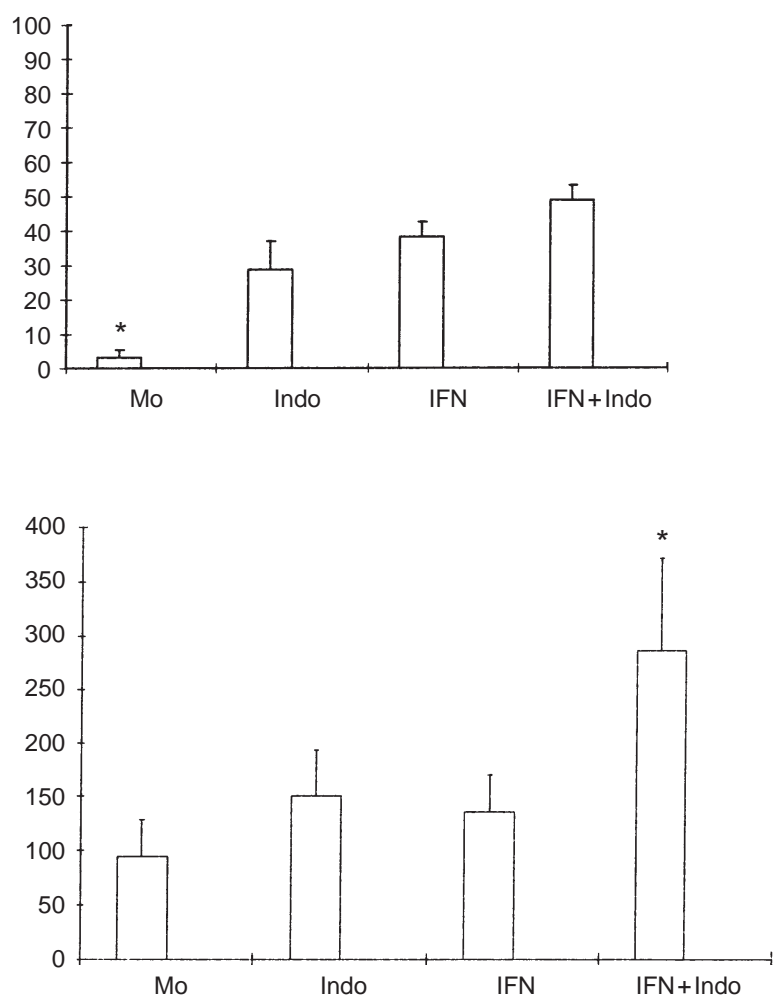

Figure 3. Correlation between fungicidal activity and TNF- $\alpha$ levels of monocytes (Mo) preincubated with CTCM or with CTCM containing Indo $(20 \mu \mathrm{g} / \mathrm{ml})$ or Indo $(20 \mu \mathrm{g} / \mathrm{ml})$ plus IFN- $\gamma(1000 \mathrm{U} / \mathrm{ml})$ for $24 \mathrm{hr}$ and after challenge with Pb18 or Pb265 for $4 \mathrm{hr}$. The results are expressed as mean \pm SEM of percentage of fungicidal activity and TNF- $\alpha$ levels detected in monocytes obtained from 15 subjects; ${ }^{*} P<0 \cdot 05,{ }^{* *} P<0 \cdot 01$.

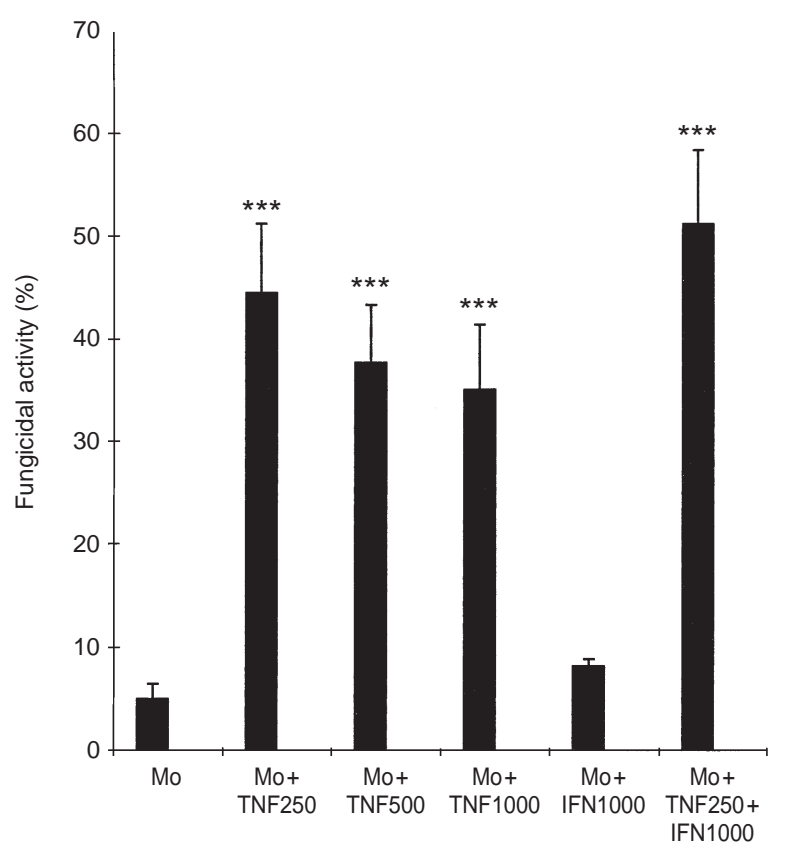

Figure 4. Fungicidal activity of monocytes (Mo) preactivated with CTCM or with CTCM plus TNF- $\alpha 250,500$ and $1000 \mathrm{U} / \mathrm{ml}$ or TNF- $\alpha$ $250 \mathrm{U} / \mathrm{ml}$ plus IFN- $\gamma 1000 \mathrm{U} / \mathrm{ml}$ and after challenge with Pb18. Results are expressed as mean \pm SEM of percentage of fungicidal activity detected in monocytes obtained from 15 subjects; $* P<0 \cdot 001$. preincubated with IFN- $\gamma$ plus anti-TNF- $\alpha$ and challenged with $\mathrm{Pb} 265$ strain. The fungicidal activity was abrogated by neutralizing antibody to TNF- $\alpha$, confirming the role for this cytokine in human monocyte activation for $P$. brasiliensis killing (Calvi et al., unpublished data).

\section{DISCUSSION}

Several mechanisms involved in the host-parasite relationship in paracoccidioidomycosis have not been fully elucidated. Since the aetiological agent is the fungus $P$. brasiliensis, which is considered an intracellular pathogen, the study of the interaction of this micro-organism with phagocytic cells is of the utmost importance in the understanding of these mechanisms. Paracoccidioides brasiliensis survives in both murine macrophages ${ }^{4}$ and human monocytes/macrophages. ${ }^{16}$ Modulation of the mononuclear phagocyte- $P$. brasiliensis interaction with cytokines has yielded conflicting results. IFN- $\gamma$ has been shown to restrict growth and survival of $P$. brasiliensis in murine macrophages. ${ }^{4}$ However, other investigators reported that IFN- $\gamma$-treated human monocytes only have a fungistatic activity against the fungus and no demonstrated fungicidal effect. ${ }^{16}$ The present results confirm these observations and others previously obtained in our laboratory in relation to the high-virulence strain of the fungus. In contrast, the IFN- $\gamma$ activated cells demonstrated an effective fungicidal activity against the low-virulence strain. In the present work we 
evaluated the modulatory effect of prostaglandins on the differences of fungicidal activity presented by human monocytes in relation to $P$. brasiliensis strains. Non-activated or IFN- $\gamma$-activated monocytes were treated with indomethacin, and then evaluated for their ability to kill $\mathrm{Pb} 18$ or $\mathrm{Pb} 265$. The results demonstrated the modulatory effect of prostaglandins even in non-activated monocytes. When these cells where not treated with indomethacin and were challenged with $\mathrm{Pb} 18$, they secreted low levels of TNF- $\alpha$ associated with a lack of fungicidal activity. However, when same cells were treated with indomethacin, low levels of TNF- $\alpha$ were produced, in the co-culture supernatant but with effective fungicidal activity. These results demonstrate that when prostaglandins are inhibited, low concentrations of TNF- $\alpha$ are sufficient for monocyte activation and consequent killing of the fungus. The same mechanism can be proposed on the basis of the results for cells treated or not with indomethacin and challenged with $\mathrm{Pb} 265$. TNF- $\alpha$ levels were higher than those obtained when the cells were challenged with $\mathrm{Pb} 18$, but no significant differences in the TNF- $\alpha$ levels were detected between the supernatants of untreated or indomethacin-treated monocytes. However, a significant fungicidal activity was detected in the treated co-cultures.

Important differences with respect to the two $P$. brasiliensis strains can be discussed in relation to the cells preincubated with IFN- $\gamma$ alone. In the co-cultures challenged with $\mathrm{Pb} 18$, low levels of TNF- $\alpha$ associated with the absence of fungicidal activity were detected. In contrast, the challenge with Pb265 stimulated a release of higher levels of TNF- $\alpha$ and the presence of effective fungicidal activity. Thus, the killing of the $\mathrm{Pb} 265$ strain by IFN- $\gamma$-activated monocytes is due to its higher capacity to induce the liberation of TNF- $\alpha$ by monocytes, supporting our hypothesis that in the presence of prostaglandins the cells must be activated by two signals one given by IFN- $\gamma$ and other by adequate concentrations of TNF- $\alpha$. Paracoccidioides brasiliensis probably induces the release of prostaglandins and other cytokines during its interaction with the phagocytic cells. Currently, results in our laboratory demonstrate that $\mathrm{Pb} 18$ induces high levels of anti-inflammatory IL-10 cytokine during monocyte infection when compared with $\mathrm{Pb} 265$. This evidence allows us to assume that strains such as $\mathrm{Pb} 265$, with minor virulence and capacity to induce the release of high levels of TNF- $\alpha$, will be destroyed more effectively. Thus the fungus-killing by phagocytic cells may be dependent on the balance of mediators with pro- or anti-inflammatory activity produced during the contact between $P$. brasiliensis and monocytes.

High production of $\mathrm{PGE}_{2}$ by macrophages leading to in vivo immune suppression has also been demonstrated in studies of intracellular infection in mice. ${ }^{17}$ In addition, this mediator promotes a generalized block of macrophage activation induced by live Mycobacterium leprae, ${ }^{12,18,19}$ Leishmania donovani $^{20}$ and Mycobacterium microti. ${ }^{21}$

In the present study although $\mathrm{Pb} 265$ induced higher levels of TNF- $\alpha$ in monocyte cultures than Pb18, similar levels of TNF- $\alpha$ were detected in supernatants of monocytes treated or not with indomethacin. Although some investigators have reported inhibition of TNF- $\alpha$ secreted by stimulated human monocytes ${ }^{22,23}$ and murine macrophages ${ }^{24}$ after the addition of exogenous $\mathrm{PGE}_{2}$, our results suggest that this mediator may exert its effect by a mechanism other than inhibition of TNF- $\alpha$ production. Choi et al. ${ }^{25}$ demonstrated that $\mathrm{PGE}_{2}$ stimulation of the human monocytic cell line THP-1 not only regulates TNF- $\alpha$ activity at the production level, but does so through the release of two soluble receptors as well. This arachidonic acid metabolite exerts a regulatory effect on TNF- $\alpha$ biological activity by interfering with its ability to interact with cell membrane TNF- $\alpha$ receptors. Thus, we assume that prostaglandins may act by inhibiting the action of the secreted TNF$\alpha$. This hypothesis could explain the need for a first signal given by IFN- $\gamma$ and another given by considerable concentrations of TNF- $\alpha$. High levels of TNF- $\alpha$ may exert a compensatory effect on the inhibition of this cytokine function by prostaglandins. The finding that in the presence of prostaglandins, monocytes need to be incubated with IFN- $\gamma$ as a first signal, to acquire effective killing ability against $P$. brasiliensis, can have important implications in vivo since a specific Th1-mediated immune response with production of IFN- $\gamma$ is crucial to the destruction of the fungus by monocytes/macrophages. However, several reports have indicated that this type of immune response is depressed in paracoccidioidomycosis patients. ${ }^{26}$

The importance of IFN- $\gamma$ has been demonstrated in murine experimental models of susceptibility and resistance to paracoccidioidomycosis. The treatment of intratracheal infected mice with anti-IFN- $\gamma$ monoclonal antibody prevented the clearance of yeast cells from the lungs and promoted their dissemination to the liver and the spleen. ${ }^{27}$

Taken together, the present results allow us to hypothesize the mechanisms involved in the early events in the interaction of $P$. brasiliensis with lung tissue. Contact of the fungus with alveolar macrophages induces an activation process with consequent release of TNF- $\alpha$, the levels of which will depend on the strain involved. However, during this activation, there is also a release of high levels of prostaglandins.

Some studies have demonstrated that antigens with the capacity to induce $\mathrm{PGE}_{2}$ release from macrophages may influence the development of a Th1 or Th2 dominant response. Thus, an inflammatory process that leads to a local increase of $\mathrm{PGE}_{2}$ might control an immune response toward dominant production of Th2-associated cytokines. $^{28}$

Macrophages infected with $M$. leprae are refractory to IFN$\gamma$-induced activation ${ }^{18}$ and generate high levels of $\mathrm{PGE}_{2}$ ex vivo. ${ }^{19}$ IFN- $\gamma$ refractory macrophages can be generated in vitro as well by infection with a large number of viable $M$. leprae bacilli, and $\mathrm{PGE}_{2}$ plays a crucial role in the induction of this defect. $^{12}$

In this context, the lack of fungicidal activity in patients and in mice susceptible to $P$. brasiliensis will occur due to an absence of IFN- $\gamma$ activation.

In conclusion, our studies need to be viewed within the context of the highly complex and extensively studied macrophage/T-cell interaction, since a wide variety of soluble factors have been implicated in both positive and negative regulation of the activation of these two cell types.

\section{REFERENCES}

1 Carbonell LM. Ultrastructure of dimorphic transformation in Paracoccidioides brasiliensis. J Bacteriol 1969; 100:1076-8.

2 Franco M, Pôncio-Mendes R, Moscardi-Bacchi M, RezkallahIwasso MT, Montenegro MR. Paracoccidioidomycosis. Bailliere's Clin Trop Med Commun Dis 1989; 4:185-220. 
3 Mcewen JG, Bedoya V, Patino MM, Salazar ME, Restrepo A. Experimental murine paracoccidioidomycosis induced by inhalation of conidia. J M Vet Mycol 1987; 25:165-75.

4 Brummer E, Hanson LH, Retrepo A, Stevens DA. In vivo and in vitro activation of pulmonary macrophages by IFN- $\gamma$ for enhanced killing of Paracoccidioides brasiliensis or Blastomyces dermatitidis. J Immunol 1988; 140:2786-9.

5 Brummer E, Hanson LH, Restrepo A, Stevens DA. Intracellular multiplication of Paracoccidioides brasiliensis in macrophages: Killing and restriction of multiplication by activated macrophages. Infect Immun 1989; 57:2289-99.

6 Mcewen JG, Brummer E, Stevens DA, Restrepo A. Effect of murine polymorphonuclear leukocytes on the yeast form of Paracoccidioides brasiliensis. Am J Trop Med Hyg 1987; 36:603-8.

7 Brummer E, Hanson LH, Stevens DA. Gamma-interferon activation of macrophages for killing of Paracoccidioides brasiliensis and evidence of non oxidative mechanisms. Int $\mathrm{J}$ Immunopharmacol 1988; 10:945-52.

8 Phipps RP, Stein SH, Roper RL. A new view of prostaglandin E regulation of the immune response. Immunol Today 1991; 12:349-52.

9 Goodwin JS, Ceuppens J. Regulation of the immune response by prostaglandins. J Clin Immunol 1983; 3:295-315.

10 Gordon D, Bray AM, Morley J. Control of lymphokine secretion by prostaglandins. Nature 1976; 262:401-2.

11 Snyder DS, Beller DI, Unanue ER. Prostaglandins modulate macrophage Ia expression. Nature 1982; 299:163-5.

12 Sibley LD, Krahenbuhl JL. Induction of unresponsiveness to gamma interferon in macrophages infected with Mycobacterium leprae. Infect Immun 1988b; 56:1912-9.

13 fava Netto C, Vegas VS, Sciannamea IM, Guarnieri DB. Antígeno polissacarídico do Paracoccidioides brasiliensis: Estudo do tempo de cultivo do $P$. brasiliensis necessário ao preparo do antígeno. Rev Inst Med Trop S Paulo 1969; 11:177-81.

14 Singer-Vermes LM, Ciavaglia MC, Kashino SS, Burger E, Calich VLG. The source of the growth-promoting factor (s) affects the plating efficiency of Paracocccidioides brasiliensis. J Med Vet Mycol 1992; 130:261-3.

15 Godfrey KAM. Statistics in practice. Comparing the means of several groups. N Engl J Med 1985; 313:450-6.

16 Moscardi-Bacchi M, Brummer E, Stevens DA. Support of Paracoccidioides brasiliensis multiplication by human monocytes or macrophages: inhibition by activated phagocytes. J Med Microbiol 1994; 40:159-64.
17 Edwards CK, Hedegaard HB, Zlotnik A, Gangadharam PR, Johnson RB, Pabst MJ. Chronic infection due to Mycobacterium intracellulare in mice: association with macrophage release of prostaglandin $E_{2}$ and reversal by injection of indomethacin, muramyl dipeptide or interferon-gamma. J Immunol 1986; 136:1820-7.

18 Sibley LD, Krahenbuhl JL. Mycobacterium leprae-burdened macrophages are refractory to activation by gamma interferon. Infect Immun 1987; 55:446-50.

19 Sibley LD, Krahenbuhl JL. Defective activation of granuloma macrophages from Mycobacterium leprae-infected nude mice. J Leukocyte Biol 1988; 43:60-6.

20 Reiner NE, Ng W, McMaster WR. Parasite accessory cell interactions in murine leishmaniasis. II. Leishmania donovani suppresses macrophage expression of class I and class II major histocompatibility complex gene products. J Immunol 1987; 138:1926-32.

21 Kaye PM, Sims M, Feldmann M. Regulation of macrophage accessory cell activity by mycobacteria. I. In vitro inhibition of Ia expression by Mycobacterium microti. Clin Exp Immunol 1986; 64:28-34.

22 Hart PH, Whitty GA, Piccoli DS, Hamilton JA. Control by IFN- $\gamma$ and $\mathrm{PGE}_{2}$ of TNF $\alpha$ and IL-1 production by human monocytes. Immunology 1989; 66:376-83.

23 Spatafora M, Chiappara G, D'Amico D, Volpes D, Melis M, Pace E, Merendino A. Effect of indomethacin on the kinetics of tumor necrosis factor alpha release and tumor necrosis factor alpha gene expression by human blood monocytes. Pharmacol Res 1991; 23:247-57.

24 Kunkel SL, Spengler M, May MA, Spengler R, Larrick J, Remick D. Prostaglandin $\mathrm{E}_{2}$ regulates macrophage-derived tumor necrosis factor gene expression. J Biol Chem 1988; 263:5380-4.

25 Choi SS, Gatanaga M, Granger GA, Gatanaga T. Prostaglandin- $E_{2}$ regulation of tumor necrosis factor receptor release in human monocytic THP-1 cells. Cell Immunol 1996; 170:178-84.

26 Musatti CC, Peraçoli MTS, Soares AMVC, Rezkallah-Iwasso MT. Cell-mediated immunity in patients with paracoccidioidomycosis. In: Paracoccidioidomycosis, eds. Franco MF, Lacaz CS, Restrepo, A, Del Negro G. 2nd edn. Boca Raton: CRC Press Boca Raton, 1994:175-86.

27 Cano LE, Kashino SS, Arruda C, et al. Protective role of gamma interferon in experimental pulmonary paracocidioidomycosis. Infect Immun 1998; 66:800-6.

28 Betz M, Fox BS. Prostaglandin $E_{2}$ inhibits production of Th1 lymphokines but not of Th2 lymphokines. J Immunol 1991; 146:108-13. 